\title{
Kajian Drainase Stadion Bhakti Karya yang Berwawasan Lingkungan Kabupaten Tanjung Jabung Barat
}

\author{
Azwarman \\ Teknik Sipil Universitas Batanghari Jambi \\ Correspondence email: warman2789@gmail.com
}

\begin{abstract}
Abstrak. Permasalahan yang sering terjadi dan hampir semua lapangan olah raga adalah timbulnya genangan air ketika datang hujan. Keberadaan genangan air akan mengganggu para pemain disaat bertanding, resiko terjatuh dan cidera. Penelitian ini bertujuan untuk mengatasi hal tersebut di Stadion bola kaki Bhakti Karya, Kuala Tungkal. Hasil analisis menunjukkan bahwa untuk mengatasi genangan air saat hujan di lapangan bola kai tersebut, dibutuhkan perbaikan berupa penambahan lapisan yang bisa mengairkan air permkaan ke drainase keliling lapanganm, selain meresapkannya ke dalam tanah.
\end{abstract}

Kata Kunci: Intensitas hujan; lapisan tanah; dimensi drainase

\section{PENDAHULUAN}

Kota Kuala Tungkal adalah salah satu kota di Kabupaten Tanjung Jabung barat yang dalam Provinsi Jambi. Stadion atau Lapangan Olah Raga merupakan sarana penting yang dimiliki oleh Warga Kab.Tanjung Barat. Permasalahan yang sering terjadi dan hampir semua lapangan olah raga adalah timbulnya genangan air ketika datang hujan. Keberadaan genangan air akan mengganggu para pemain disaat bertanding, resiko terjatuh dan cidera. Masalah genangan air di Lapangan ini sangat terkait dengan sistem rancangan pembuangan air yang berlebihan dalam hal ini drainase permukaan dan drainase bawah permukaan yang ada di Stadion Olah Raga tersebut. Faktor pendukung drainase supaya dapat bekerja dengan baik, seperti kondisi tanah, operasi dan pemeliharan harus mendapat perhatian khusus .

Tujuan Penelitian drainase di lapangan sepak bola Stadion Bhakti Karya ini adalah untuk mencegah atau mengurangi timbulnya genangan air di lapangan dan di sekitarnya ketika hujan turun.

Permasalahan yang menjadi pembahasan dari penelitian ini adalah :

Pada waktu hujan terjadi genangan air pada lapangan sehingga menghambat laju bola dan juga membahayakan pemain di lapangan.

1. Kondisi peresapan lapangan yang belum memadai mempengaruhi permukaan lapangan sehingga menimbulkan genangan/limpasan.

2. Bagaimana perencanaan sumur peresapan yang bisa mengatasi masalah genangan permukaan pada lapangan sepak bola.

3. Menormalisasi saluran drainase yang ada, dengan merencanakan dimensi saluran drainase yang optimal.

4. Berapa dimensi dan jarak efektif pemasangan pipa drain.

Siklus hidrologi adalah proses perjalanan air secara kontinyu dari danau atau laut ke atmosfer yang merupakan uap (evaporasi) dan dari atmosfer digerakkan oleh angin menuju tempat yang tekanan udaranya renggang dan dimana terdapat proses pendinginan dan setelah itu terjadi proses pencairan menjadi hujan yang jatuh kebumi. Sebelum sampai dibumi membasahi daun-daunan dulu dan terjadi penguapan lagi dari dedaunan (transpirasi) dan yang jatuh ke permukaan bumi menjadi aliran permukaan (run off) dan masuk lagi ke sungai atau danau. Sebagian lagi akan meresap kedalam tanah (infiltrasi) dan dalam tanah akan mengalir lagi menuju tempat yang lebih rendah atau sungai. Proses pengulangan yang terus menerus ini merupakan serangkaian peristiwa dimana kita tidak tahu kapan dan darimana awalnya serta kapan akan berakhirnya (Suripin 2004).

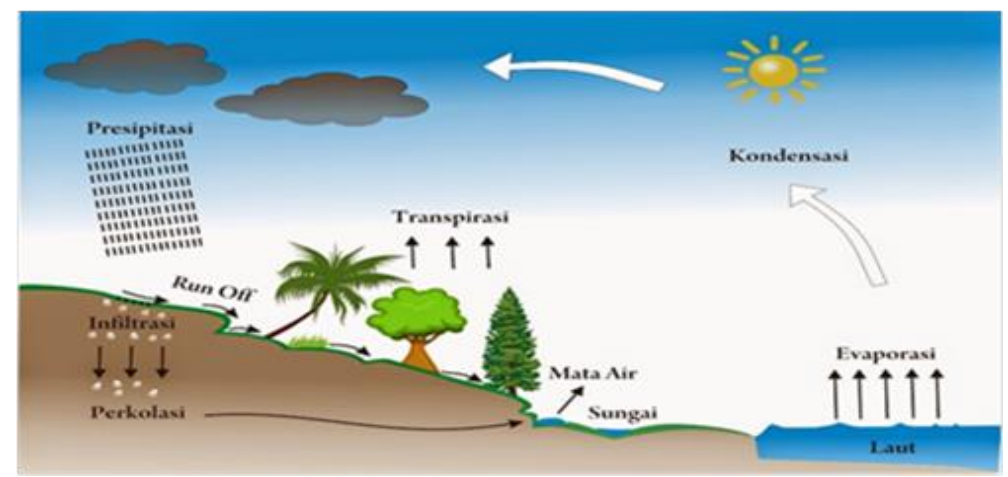

Gambar 1. Siklus Hidrologi 
$I=\frac{\mathrm{Rt}}{\mathrm{t}}$

Untuk menentukan Itensitas hujan selama waktu kosentrasi, (Hadisusanto, 2010), dapat digunakan rumus:

Talbot

$I=\frac{\mathrm{a}}{\mathrm{t}+\mathrm{b}}$

Ishiguro

$I=\frac{\mathrm{a}}{\sqrt{\mathrm{t}}+\mathrm{b}}$

Sherman

$I=\frac{\mathrm{a}}{\mathrm{t}^{\mathrm{n}}}$

Menghitung Curah Hujan Dengan Metode Analisa Frekwensi

Metode Gumbel

Persamaan yang digunakan dalam analisis statistik Gumbel dapat ditulis sebagai berikut: (Suripin, 2004).

$\mathrm{X}=\overline{\mathrm{X}}+\mathrm{K}_{\mathrm{T}} \mathrm{S}$

Keterangan :

$\overline{\mathrm{X}} \quad=$ Nilai rata - rata curah hujan $\mathrm{N}$ pertahun $(\mathrm{mm})$

$\mathrm{S} \quad=$ Standar deviasi (simpangan baku)

Faktor $\mathrm{K}_{\mathrm{T}}$ untuk harga rata - rata ekstrim Gumbel

\section{Metode Log Person Tipe III}

Berikut ini langkah - langkah penggunaan distribusi Log Person Tipe III (Suripin, 2004).

Hitung Logaritma hujan atau banjir dengan periode ulang $\mathrm{T}$ dengan rumus:

$\log \mathrm{X}_{\mathrm{Tr}}=\log \overline{\mathrm{x}}+\mathrm{K}_{\mathrm{T}} \mathrm{s}$

\section{Menentukan Dimensi Saluran Drainase}

Dimensi saluran harus mampu mengalirkan debit rencana atau dengan kata lain debit yang dialirkan oleh saluran $(\mathrm{Qs})$ sama atau lebih besar dari debit rencana $\left(\mathrm{Q}_{\mathrm{R}}\right)$. Hubungan ini ditunjukkan sebagai berikut : (Wesli, 2008)

$\mathrm{QR} \geq \mathrm{QE}$

Debit Eksisting suatu penampang saluran (QE) dapat diperoleh dari hasil pengukuran lansung di Lapangan dan dengan menggunakan rumus seperti di bawah ini.

\section{Mencari luas penampang saluran}

$\mathrm{AE}=\mathrm{QE} / \mathrm{V}$

Mencari tinggi Saluran

$\mathrm{H}=\sqrt{\mathrm{As}}$

\section{Mencari lebar saluran}

$\mathrm{B}=\sqrt{\mathrm{As}}$

\section{Mencari debit kontrol}

$\mathrm{QE}=\mathrm{AE} . \mathrm{V}$

Dalam Desain debit rencana menggunakan Formula Metode rasional dengan menghitung terlebih dahulu Intensitas hujan, dan menentukan luas areal atau cathment area drainase tersebut. Formula Metode Rasional: (Wesli, 2008) adalah $\mathrm{Q}_{\mathrm{R}}=0,00278$.C.I.A 


\section{METODE}

Lokasi penelitian berada di Kecamatan Tungkal Ilir Kabupaten Tanjung Jabung Barat Provinsi Jambi, tepatnya di Jalan Ki Hadjar Dewantara. Prosedur kerja penelitian dapat dilihat pada Flowchart berikut ini:

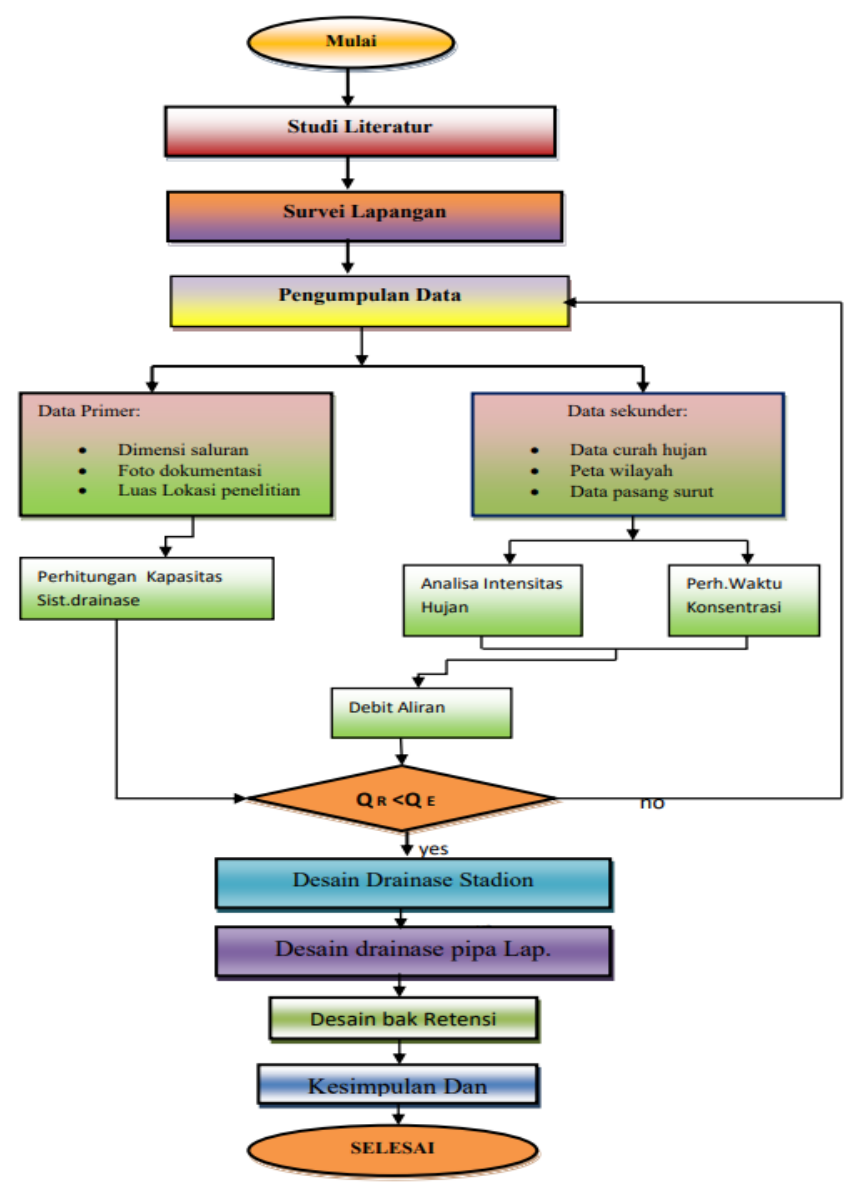

Gambar 1. Alur Penelitian Stadion Bhakti Karya

\section{HASIL DAN PEMBAHASAN}

Tabel 1. Hasil Perhitungan Curah Hujan Rencana dengan dua Metode

\begin{tabular}{clcccccc}
\hline \multirow{2}{*}{ No } & \multirow{2}{*}{ Metode } & \multicolumn{5}{c}{ Periode Ulang /Tahun (mm/hari) } \\
\cline { 3 - 7 } & \multicolumn{1}{c}{ G } & $\mathbf{2}$ & $\mathbf{1 0}$ & $\mathbf{2 5}$ & $\mathbf{5 0}$ & $\mathbf{1 0 0}$ \\
\hline 1 & Gumbel & 174,140 & 195,193 & 209,132 & 226,744 & 239,149 & 252,779 \\
2 & Log Pearson Tipe III & 174,621 & 190,387 & 199,968 & 211,312 & 219,351 & 247,646 \\
\hline
\end{tabular}

Sumber : Hasil Perhitungan 2020

\section{Uji Kecocokan Distribusi}

Tabel 2. Uji Smirnov - Kolmogorov Metode Gumbel

\begin{tabular}{|c|c|c|c|c|c|c|c|c|}
\hline $\mathbf{m}$ & $\mathbf{x}$ & $x$ terurut & $P(x)=m /(n+1)$ & $1-p(x \leq)$ & $F(t)=(x-x) / S$ & $\mathbf{p}^{\prime}(\mathbf{x})$ & $p^{\prime}(x \geq)-1$ & $\Delta \mathbf{p}$ \\
\hline 1 & 187,250 & 152,000 & 0,091 & 0,909 & $-1,391$ & 0,014 & $-1,014$ & $-1,028$ \\
\hline 2 & 212,917 & 159,667 & 0,182 & 0,818 & $-0,956$ & 0,018 & $-1,018$ & $-1,036$ \\
\hline 3 & 171,250 & 164,083 & 0,273 & 0,727 & $-0,705$ & 0,020 & $-1,020$ & $-1,040$ \\
\hline 4 & 166,000 & 166,000 & 0,364 & 0,636 & $-0,597$ & 0,021 & $-1,021$ & $-1,041$ \\
\hline 5 & 181,667 & 171,250 & 0,455 & 0,545 & $-0,299$ & 0,022 & $-1,022$ & $-1,044$ \\
\hline 6 & 186,500 & 181,667 & 0,545 & 0,455 & 0,292 & 0,022 & $-1,022$ & $-1,044$ \\
\hline 7 & 159,667 & 183,917 & 0,636 & 0,364 & 0,419 & 0,022 & $-1,022$ & $-1,043$ \\
\hline 8 & 164,083 & 186,500 & 0,727 & 0,273 & 0,566 & 0,021 & $-1,021$ & $-1,042$ \\
\hline 9 & 152,000 & 187,250 & 0,818 & 0,182 & 0,608 & 0,021 & $-1,021$ & $-1,041$ \\
\hline 10 & 183,917 & 212,917 & 0,909 & 0,091 & 2,064 & 0,008 & $-1,008$ & $-1,016$ \\
\hline \multicolumn{2}{|c|}{$\begin{array}{c}\text { Rerata } x \\
\text { Standar deviasi (s) }\end{array}$} & $\begin{array}{c}176,525 \\
17,635\end{array}$ & & & & & $\Delta$ Hitung & $-10,376$ \\
\hline
\end{tabular}

Sumber : Hasil Perhitungan 2020 
Kesimpulan :

Untuk $\mathrm{n}=10$ dengan derajat kepercayaan $\Delta=5 \%$ didapat $\Delta$ Kritis $=0,41$

$\Delta$ Hitung $\leq \Delta$ Kritis

$-\mathbf{1 0 , 3 7 6} \leq \mathbf{0 , 4 1} \rightarrow$ Metode Gumbel dapat dipakai.

Tabel 3. Uji Smirnov - Kolmogorov Metode Log Person Tipe III

\begin{tabular}{|c|c|c|c|c|c|c|c|c|}
\hline m & $\mathbf{x}$ & $\log x$ & $P=m /(n+1)$ & 1-P(x) & $\mathbf{f}(\mathbf{t})=(\mathbf{x}-\mathbf{x}) / \mathbf{s}$ & $\mathbf{p}^{\prime}(\mathbf{x})$ & $p^{\prime}(x \geq)-1$ & D \\
\hline 1 & 152,000 & 2,182 & 0,091 & 0,909 & $-1,482$ & 0,014 & $-0,986$ & $-1,000$ \\
\hline 2 & 159,667 & 2,203 & 0,182 & 0,818 & $-0,980$ & 0,018 & $-0,982$ & $-1,000$ \\
\hline 3 & 164,083 & 2,215 & 0,273 & 0,727 & $-0,701$ & 0,020 & $-0,980$ & $-1,000$ \\
\hline 4 & 166,000 & 2,220 & 0,364 & 0,636 & $-0,583$ & 0,021 & $-0,979$ & $-1,000$ \\
\hline 5 & 171,250 & 2,234 & 0,455 & 0,545 & $-0,265$ & 0,022 & $-0,978$ & $-1,000$ \\
\hline 6 & 181,667 & 2,259 & 0,545 & 0,455 & 0,338 & 0,022 & $-0,978$ & $-1,000$ \\
\hline 7 & 183,917 & 2,265 & 0,636 & 0,364 & 0,463 & 0,022 & $-0,978$ & $-1,000$ \\
\hline 8 & 186,500 & 2,271 & 0,727 & 0,273 & 0,606 & 0,021 & $-0,979$ & $-1,000$ \\
\hline 9 & 187,250 & 2,272 & 0,818 & 0,182 & 0,646 & 0,021 & $-0,979$ & $-1,000$ \\
\hline 10 & 212,917 & 2,328 & 0,909 & 0,091 & $-1,957$ & 0,008 & $-0,992$ & $-1,000$ \\
\hline \multicolumn{2}{|c|}{$\begin{array}{c}\text { Rerata } x \\
\text { Standar deviasi (s) }\end{array}$} & $\begin{array}{c}2,245 \\
0,0426\end{array}$ & & & & & $\Delta$ Hitung & $-10,000$ \\
\hline
\end{tabular}

Sumber : Hasil Perhitungan 2020

Kesimpulan :

Untuk $n=10$ dengan derajat kepercayaan $\Delta=5 \%$ didapat $\Delta$ Kritis $=0,41$

$\Delta$ Hitung $\leq \Delta$ Kritis

$-\mathbf{1 0 , 0 0 0} \leq \mathbf{0 , 4 1} \rightarrow$ Metode Log Person Tipe III dapat dipakai

Tabel 4. Hasil Pengujian Data Curah Hujan Maksimum Metode Smirnov - Kolmogorov

\begin{tabular}{clccc}
\hline \multirow{2}{*}{ No } & Metode & \multicolumn{3}{c}{ Periode Ulang } \\
\cline { 3 - 5 } & & Nilai Kritis (Do) & Nilai D maks & Keterangan \\
\hline 1 & Metode Gumbel & 0,41 & $-10,376$ & Lebih Cocok \\
2 & Metode Log Person III & 0,41 & $-10,000$ & Cocok \\
\hline
\end{tabular}

Sumber : Hasil Perhitungan 2020

Tabel 5. Hasil Perhitungan Konstanta lamanya Hujan (a,b,n)

\begin{tabular}{cccccccc}
\hline Periode & \multicolumn{2}{c}{ TALBOT } & \multicolumn{2}{c}{ ISHIGURO } & \multicolumn{3}{c}{ SHERMAN } \\
\hline Ulang (T) & $\mathbf{a}$ & $\mathbf{b}$ & $\mathbf{a}$ & $\mathbf{b}$ & Log a & $\mathbf{a}$ & $\mathbf{n}$ \\
\hline 2 & 2585,496 & 18,134 & 241,490 & $-0,378$ & 2,499 & 315,506 & 0,555 \\
5 & 4049,400 & 20,217 & 377,648 & $-0,180$ & 2,626 & 423,121 & 0,523 \\
10 & 4681,810 & 18,134 & 437,290 & $-0,378$ & 2,757 & 571,317 & 0,555 \\
25 & 5812,336 & 18,134 & 542,884 & $-0,378$ & 2,851 & 709,275 & 0,555 \\
50 & 7156,880 & 18,134 & 668,467 & $-0,378$ & 2,941 & 873,348 & 0,555 \\
100 & 7564,767 & 18,134 & 706,564 & $-0,378$ & 2,965 & 923,122 & 0,555 \\
\hline
\end{tabular}

Sumber : Hasil Perhitungan 2020

Tabel 6. Hasil Perhitungan Intensitas durasi Tiga Metode Periode Ulang 10 tahun

\begin{tabular}{ccccc}
\hline \multirow{2}{*}{ No } & Durasi & Metode Talbot & Metode Ishiguro & Metode Sherman \\
\cline { 2 - 5 } & (menit) & $\mathbf{1 0}$ Tahun & 10 Tahun & 10 Tahun \\
\hline 1 & 5 & 202,378 & 235,342 & 234,013 \\
2 & 10 & 166,411 & 157,055 & 159,328 \\
3 & 20 & 122,773 & 106,808 & 108,479 \\
4 & 30 & 97,266 & 85,756 & 86,634 \\
5 & 40 & 80,535 & 73,536 & 73,858 \\
6 & 60 & 59,920 & 59,350 & 58,985 \\
7 & 80 & 47,708 & 51,048 & 50,287 \\
8 & 120 & 33,893 & 41,346 & 40,160 \\
\hline
\end{tabular}

Sumber : Hasil perhitungan 2020 


\section{Grafik Intensitas Durasi Tiga Metode}

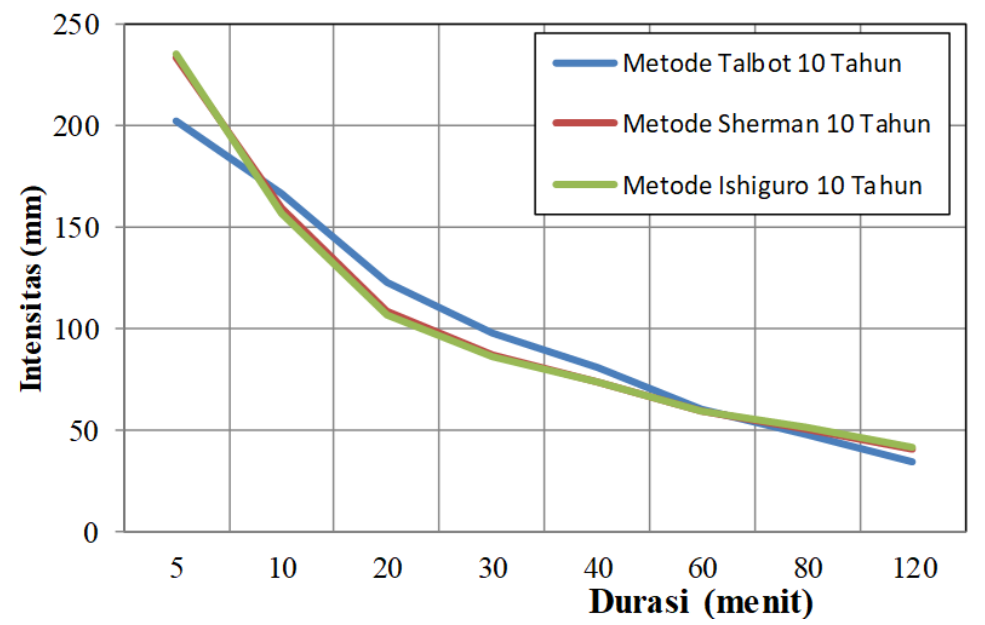

Gambar 2. Grafik IDF Talbot-Sherman-Ishiguro

\section{Perhitungan Diameter Pipa drain Lapangan}

Drainase ini harus cukup andal agar di musim hujan permainan sepak bola masih bisa diteruskan. Untuk itu harus ada perbaikan sistem drainase lapangan dengan membuat perbaikan tanah setebal 0,60 $\mathrm{m}$ yang terdiri dari top layer, setebal $15 \mathrm{~cm}$, terdiri dari pasir urug dan pupuk kandang, dengan perbandingan 2:1 (agar rumput masih bisa tumbuh subur dan baik). Di bawahnya ada lapisan pasir urug $10 \mathrm{~cm}$. Di bawahnya lagi ada pasir murni setebal $5 \mathrm{~cm}$, dan seterusnya ada lapisan kerikil $\varnothing 5 \mathrm{~mm}$ setebal $5 \mathrm{~cm}$. Ada lapisan yang paling bawah setebal setebal $20 \mathrm{~cm}$ berupa batu koral $\varnothing 20 \mathrm{~mm}$. Kecepatan meresap kedalam lapisan tersebut $6 \mathrm{~m}$ /hari dan porositas $40 \%$. Pipa drain sedalam $0,60 \mathrm{~m}$ dan berjarak $5 \mathrm{~m}$ satu sama lain, dibuat memanjang antar tiang gawang dengan kemiringan pipa 0,01 dan panjang pipa drain $120 \mathrm{~m}$.

Perencanaannya meliputi:

a. Berapa diameter pipa yang dipakai,

b. Bagaimana cara penempatan pipa drainase di lapangan tersebut .

c. Sket saluran pembuangan atau selokan pada pinggiran lapangan

Analisis masalah dicoba sebagai berikut :

- Di atas permukaan lapangan tentu terdapat kelebihan air yang tidak meresap dan akan mengalir melalui permukaan, masuk selokan sekeliling (collector drain) .Aliran permukaan diberi kemiringan 0,07

- Menghitung diameter pipa drain di bawah tanah di lapangan :

$\mathrm{P}=40 \%$ (porositas)

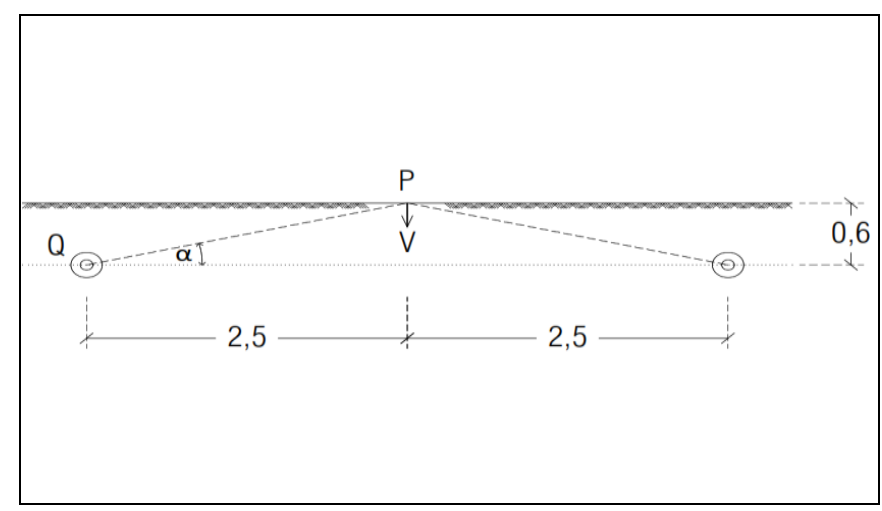

Gambar 3. Sistem Penempatan Pipa Drain di Lapangan

$\mathrm{V}=6 \mathrm{~m} / \mathrm{hari}$

$\operatorname{Sin} \alpha=\frac{0,60}{\sqrt{(2,50)^{2}+(0,60)^{2}}}=0,23$

$P_{P Q}=\mathrm{V} \sin \alpha=6.0,23=1,38 \mathrm{~m} / \mathrm{hr}$

Jarak antara pipa drain $=\mathrm{B}$

Panjang pipa drain $=\mathrm{L}$

Kedalaman pipa $\quad=\mathrm{H}$ 
Waktu untuk meresapkan air dari P ke Q adalah :

$T_{P Q}=\frac{\sqrt{6,61}}{1,38}=1,86 \mathrm{hr}$

Volume pori tanah yang terisi air :

$\mathrm{I}=(0,80)$ L.B.H.P $=0,80.120 \cdot 5 \cdot 0,60 \cdot 40 \%=115,2 \mathrm{~m}^{3}$

Kapasitas drain pipa sepanjang $120 \mathrm{~m}$ :

$\mathrm{Q} 120=\frac{I}{T_{P Q}}=\frac{115,2}{1,86(24 \times 3600)}=7,17.10^{-4} \frac{\mathrm{m}^{\mathrm{a}}}{\text { det }}=0,717 \mathrm{ltr} /$ det.

Direncanakan Pipa drain hanya terisi $30 \%$ sesuai perhitungan Drain lampiran pada yang di perhitungankan, dengan debit yang diperhitungkan $20 \%$ dan debit maksimum yang di perhitungkan dalam pipa adalah seperti sbb:

$Q_{\text {pipa }}=\frac{100}{20}(0,717)=3,585 \mathrm{ltr} /$ det

Diameter pipa drain $=0,125 \mathrm{~m}=12,50 \mathrm{~cm}$

Gambar Konstruksi drainase, untuk lapisan tanah sebagai berikut :

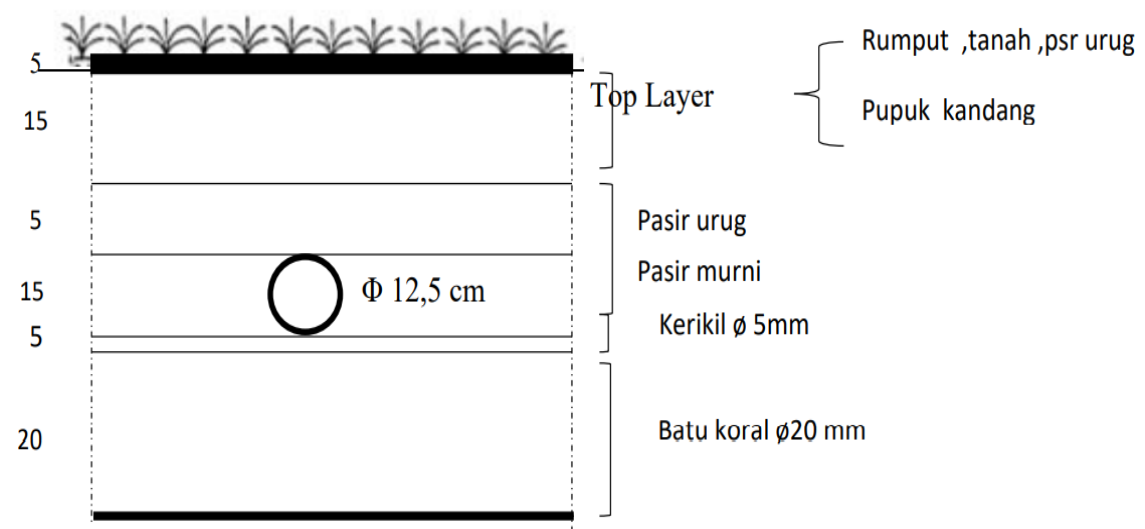

Gambar 4. Susunan Lapisan Tanah Lapangan Sepak Bola

\section{Analisa jarak antara pipa di lapangan sepak bola :}

Dari data tersebut diatas kita sudah mengetahui ketinggian elevasi lapangan dan ketinggian pasang disaat terjadi kenaikan air laut. Perbedaan ketinggian adalah Tinggi lapangan - Muka Air Pasang Tertinggi= 4,6 $\mathrm{m}-3,8 \mathrm{~m}=0,7$ meter.

Cek jarak pipa drain atau pipa pembuangan air di bawah lapangan sepak bola yang di misalkan $5 \mathrm{~m}$ seperti pemasangan gambar apakah sudah memenuhi syarat, dengan data yang diketahui sebagai berikut:

1. Jarak impervious layer terhadap permukaan tanah $=5 \mathrm{~m}$

2. Kedalaman pipa dari permukaan tanah $\quad=0,6 \mathrm{~m}=60 \mathrm{~cm}$

3. Koefisien permeabilitas tanah $\mathrm{K}$

$=50 \mathrm{~mm} / \mathrm{jam}$

4. Selisih muka air tanah

$=0,6 \mathrm{~m}$

5. Kecepatan infiltrasi $\left(V_{1}\right)$

$=50 \mathrm{~cm} / \mathrm{jam}$

Dengan menggunakan rumus dupuit:

$\mathrm{K}=5 \mathrm{~cm} / \mathrm{jam}$

$\mathrm{V} 1=50 \mathrm{~cm} / \mathrm{jam}$

a $\quad=(\mathrm{k}-$ kedalaman pipa dari permukaan tanah $)$

$=(5-0,6)=4.4 \mathrm{~m}$

$=(\mathrm{a}+$ Selisih muka air tanah $)$

b $\quad=(4,4+0,7)=5,1 \mathrm{~m}$

$\mathrm{L} \quad=2 \sqrt{\frac{\mathrm{K}}{\mathrm{V} 1}\left(\mathrm{~b}^{2}-\mathrm{a}^{2}\right)} \quad=2 \sqrt{\frac{5}{5}\left(5,1^{2}-4,4^{2}\right)}=2 \times 2,57=5,14 \mathrm{~m}$

$\mathrm{L}=\mathrm{Jarak}$ antara Pipa drain di lapangan .diambil jarak $=5 \mathrm{~m}$. Jadi jarak pemisalan awal $5 \mathrm{~m}$ cukup memenuhi syarat 


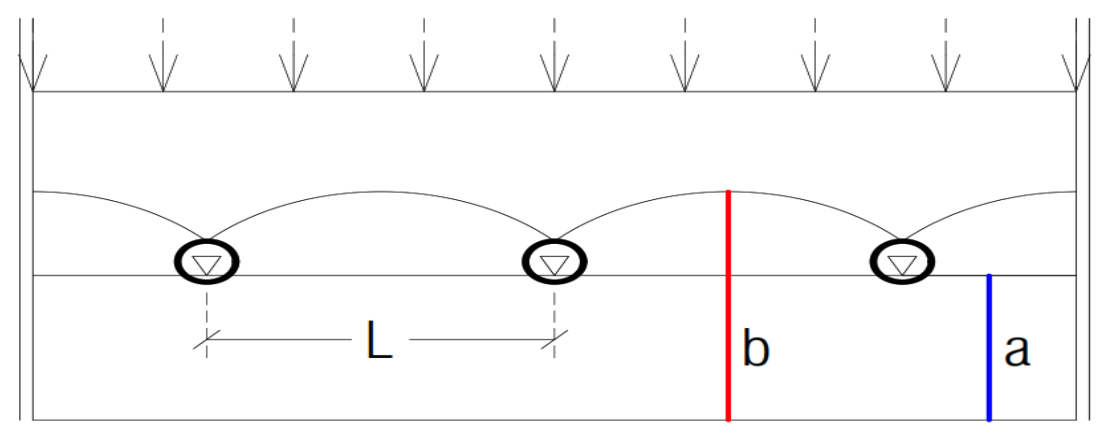

Gambar 5. Jarak antara Pipa di lapangan
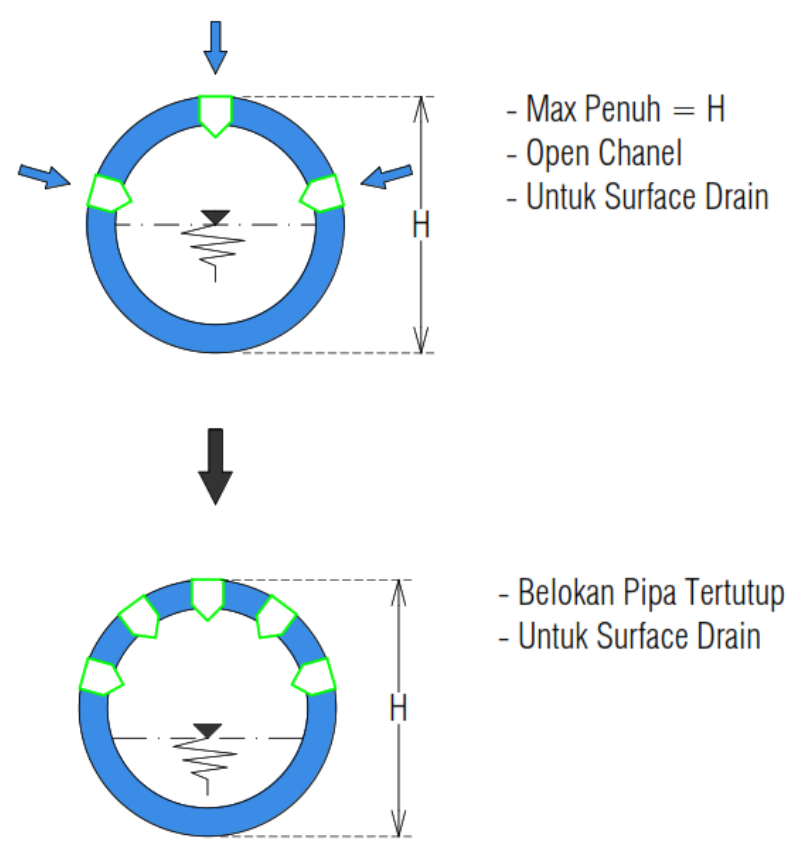

Gambar 6. Drain pipa dibawah tanah untuk pipa yang lurus dan pada belokan

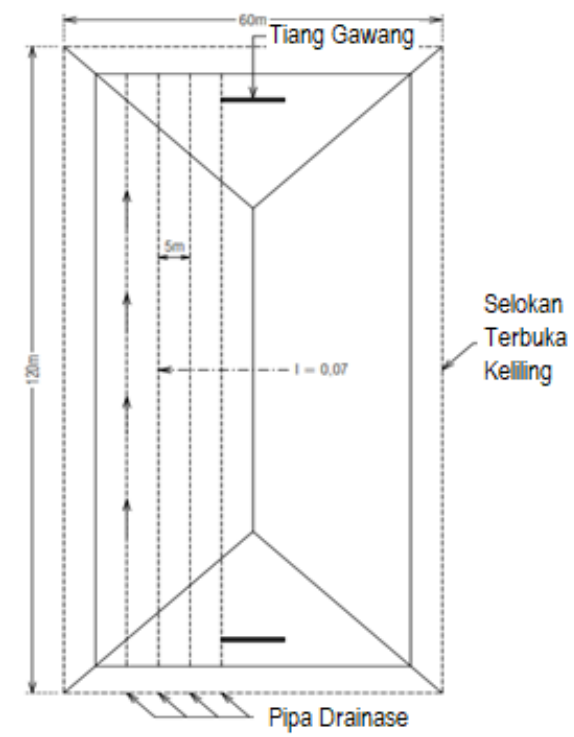

Gambar 7. Tampak atas penempatan pipa drainase

\section{Analisa Dimensi Saluran Drainase Stadion}

Untuk perhitungan dimensi saluran menggunakan debit rencana yang akan dialirkan oleh saluran drainase. Berikut perhitungan dimensi saluran (penampang persei panjang) dranase Stadion Bhakti Karya : 
1. Luas penampang

As $=\frac{Q_{\mathrm{T}}}{\mathrm{V}}, \quad$ As $=\frac{0,055}{0,3}=0,182 \mathrm{~m}^{2}$

2. Tinggi Saluran

$\mathrm{H}=\sqrt{\mathrm{As}}, \quad \mathrm{H}=\sqrt{0,42} \quad=0,42 \mathrm{~m}$ diambil $\mathrm{H}=0,5 \mathrm{~m}$

3. Lebar saluran

$\mathrm{B}=\sqrt{\mathrm{As}}, \quad \mathrm{B}=\sqrt{0,42} \quad=0,42 \mathrm{~m}$ diambil $\mathrm{B}=0,5 \mathrm{~m}$

4. Debit kontrol

$\mathrm{A}=\mathrm{B} \times \mathrm{H}=0,5 \times 0,5=0,25 \mathrm{~m}^{2} . \mathrm{QR}=\mathrm{As} . \mathrm{V}, \quad \mathrm{QR}=0,25 \times 0,3=0,075 \mathrm{~m}^{3} /$ detik

$\mathrm{QR}=\mathrm{As} . \mathrm{V}, \mathrm{QR}=0,25 \times 0,3=0,075 \mathrm{~m}^{3} /$ detik

$\mathrm{QR} \geq \mathrm{Q}_{\mathrm{T}}$

$0,075 \geq 0,055 \quad(\mathrm{Ok})$

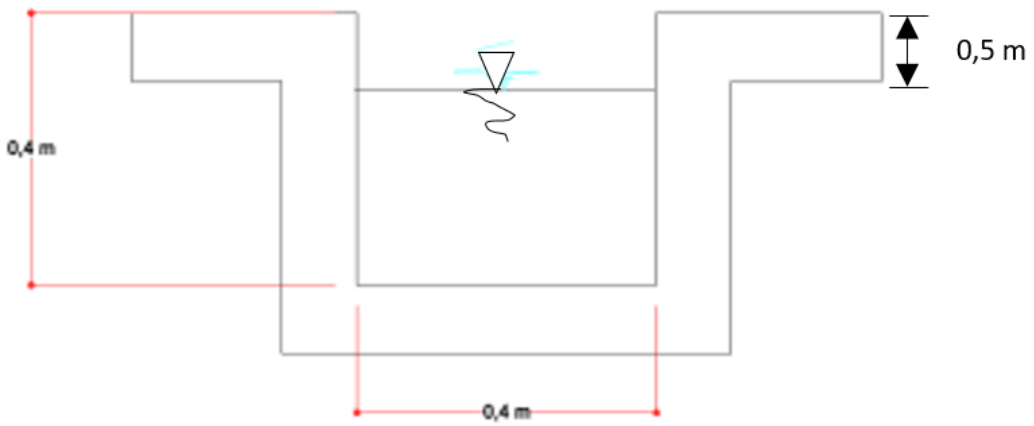

Gambar 8. Penampang persegi sal.Rencana

\section{Rencana Dimensi Kolam Retensi}

Kolam retensi adalah salah satu cara cara mengatasi banjir dalam dimana masih terdapat limpasan dari drainase setelah ada sumur resapan dalam jangka waktu tertentu sesuai prakiraan perhitungan desainnya.

1. Debit saluran

$\mathrm{Q}_{\mathrm{s}}$ Persegi panjang $=0,075 \mathrm{~m}^{3} /$ detik

$\mathrm{Q}_{\mathrm{T}}=0,055 \mathrm{~m}^{3} / \mathrm{detik}$

$\mathrm{Q}_{\text {Kolam Retensi }}=\mathrm{Q}_{\mathrm{S}}-\mathrm{Q}_{\mathrm{T}}=0,075 \mathrm{~m}^{3} / \mathrm{detik}-0,055 \mathrm{~m}^{3} / \mathrm{detik}=0,02 \mathrm{~m}^{3} / \mathrm{detik}$

Jadi $Q_{\text {Kolam Retensi }}=0,02 \mathrm{~m}^{3} /$ detik

2. Hitung waktu dan dimensi yang dibutuhkan untuk mengisi kolam retensi,dicoba dengan ukuran $\mathrm{P}=8 \mathrm{~m} \times \mathrm{L} 6 \mathrm{~m} \times$ $\mathrm{T} 3 \mathrm{~m}=144 \mathrm{~m}^{3}$

3. Lama waktu pengisian $=244 \mathrm{~m}^{3} / 0,02 \mathrm{~m}^{3} / \mathrm{det}=7200 \mathrm{det}=2 \mathrm{jam}$

Kolam retensi akan penuh dalam waktu 2 jam, sehingga cukup lama menahan limpasan air selama pertandingan sepak bola .

Maka ukuran kolam retensi tersebut bisa dipakai untuk dimensi kolam retensi.

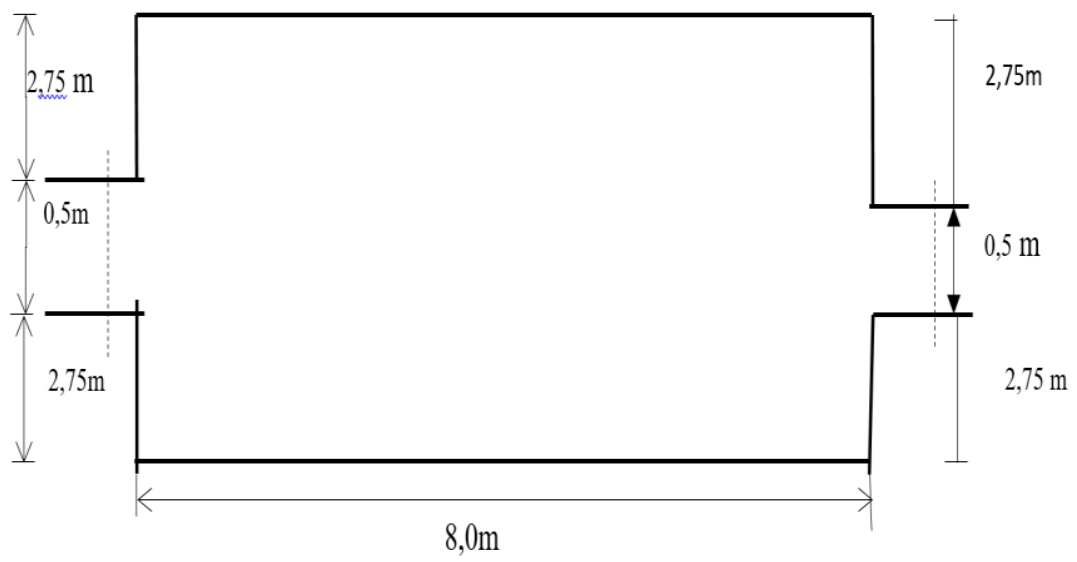

Gambar 9. Rencana Dimensi Kolam Retensi 


\section{Analisa Desain Sumur Resapan}

Suatu kawasan Lapangan sepak bola dan lapangan sekitarnya 0,74 ha $\left(120 \times 62 \mathrm{~m}^{2}\right)$ ditonton oleh 500 penonton. Tanah pada kawasan tersebut mempunyai koefisien permeabilitas $K=1,5 \times 10^{-4} \mathrm{~m} /$ detik. Diestimasi debit air yang keluar dari lapangan tersebut jika tanpa sumur resapan, dan setelah direncanakan sumur resapan, berapa dimensi sumur yang diperlukan.

Air masuk yang jatuh dari atap podium penonton sampai ke sumur resapan, $\mathrm{tc}=2 \mathrm{jam}$.

$\mathrm{Q}$ atap $=0,00278 \times \mathrm{C}_{\text {atap }} \times \mathrm{I} . \times \mathrm{A}$

$\mathrm{Q} \quad=0,00278.0,95.59,920.1,115=0,176 \mathrm{~m}^{3} / \mathrm{det}$.

Luas areal yang diperhitungkan $=1,115 \mathrm{ha}=11150 \mathrm{~m}^{2}$

Koefisien permeabilitas $\mathrm{K}=1,5 \times 10^{4} \mathrm{~m} / \operatorname{detik}$ (Asumsi)

tc $=2 \mathrm{jam}=7200 \mathrm{det}$

Diperhitungkan:

$\begin{array}{ll}\text { Halaman } & : 40 \% .250 \mathrm{~m}^{2}=100 \mathrm{~m}^{2}, \mathrm{C}=0,10 \\ \text { Atap } & : 40 \% .250 \mathrm{~m}^{2} .=100 \mathrm{~m}^{2}, \mathrm{C}=0,95 \\ \text { Jalan aspal }: 20 \% .250 \mathrm{~m}^{2}=50 \mathrm{~m}^{2} . \mathrm{C}=0,95 \\ \mathrm{C}=\frac{100 \times 0,10+100 \times 0,95+50 \times 0,95}{250}=0,61\end{array}$

Panjang lintasan terjauh $=\left(1000^{2}+298^{2}\right)^{0,5}=1,043 \mathrm{~m}$

Intensitas curah hujan 10 Tahun metode Sherman durasi 60 menit $=159,328 \mathrm{~mm} / \mathrm{jam}$

Panjang lintasan terjauh adalah $\sqrt{\left(150^{2}+72^{2}\right.}=166,39 \mathrm{~m}$

Waktu konsentrasi , ambil $\mathrm{v}=1 \mathrm{~m} / \mathrm{det}, \mathrm{Tc}=2,77$ menit.

Drainase tanpa sumuran

$\mathrm{Q}=0,00278$. C.I.A

$\mathrm{Q}=0,00278.0,61 \cdot 159,328 \cdot 0 \cdot 055=0,0148 \mathrm{~m}^{3} / \mathrm{det}$.

Ukuran Sumur Resapan

Waktu Konsentrasi tc $=2$ jam, maka :

$\mathrm{I}=\frac{7724}{(t+41,0)}=\frac{7724}{(120+41)}=48 \mathrm{~mm} / \mathrm{jam}$

$\mathrm{Q}$ maks dari atap $=\mathrm{Q}$

$\mathrm{Q}_{\text {atap }}=0,00278 . \mathrm{C}_{\text {atap }} . \mathrm{I} \cdot \mathrm{A}_{\text {atap }}$

$=0,00278 \times 0,95 \times 48 \times 100^{-4}=1,267.10^{-3} \mathrm{~m}^{3} /$ det.

\section{Ukuran Sumur Resapan}

Untuk Membangun sumur resapan agar dapat memberikan konstribusi yang optimum diperhitungkan dengan formula (Sunjoto, 1992).

Jika $F=5,5 \mathrm{R}$, gunakan diameter sumur $1 \mathrm{~m}($ jari-jari, $\mathrm{R})=0,5 \mathrm{~m}$

$H=\frac{Q}{F x K}\left(1-e^{\frac{-F x K x T}{\pi x R^{2}}}\right)$

Keterangan:

$\mathrm{H} \quad=$ Tinggi muka air dalam sumur

$\mathrm{Q} \quad=$ Debit $\mathrm{m}^{3} /$ det.

$\mathrm{F} \quad=$ Faktor geometrik $(\mathrm{m})$

$\mathrm{K} \quad=$ Kosfisien Permiabilitas $(\mathrm{m} / \mathrm{det})$

$\mathrm{R} \quad=$ Jari - Jari sumur $(\mathrm{m})$

$\mathrm{T} \quad=$ Durasi aliran $(\mathrm{det})$

$\mathrm{H}=\frac{1,267.10^{-3}}{4,125 \times 1,5 \times 10^{-4}}\left(1-e \frac{-2,75 \times 1,5 \times 10^{-4} \times 2.3600}{2,14 \times 0,5^{2}}\right)=\mathbf{3 ~ m}$

Besarnya debit setelah ada sumur resapan Karena aliran air dari atap podium dialirkan ke sumur resapan, maka aliran yang dibuang ke saluran drainase adalah air dari halaman (40\%) dan jalan (20\%), sehingga luas aliran menjadi (60\% $\mathrm{x} 1,115 \mathrm{ha})=0,669 \mathrm{ha}$.

$\mathrm{C}_{\text {composit }}=\frac{100.0,10+50.0,95}{150}=0,383$ 
$\mathrm{Q}=0,00278 . \mathrm{C} . \mathrm{I} \cdot \mathrm{A}=0,00278.0,383.59,920.0,669=0,042 \mathrm{~m}^{3} / \mathrm{det}$

Jadi dengan adanya sumur resapan terjadi pengurangan debit $=0,176-0,042=0,134 \mathrm{~m}^{3} /$ det. Atau terjadi pengurangan debit 76,13\%

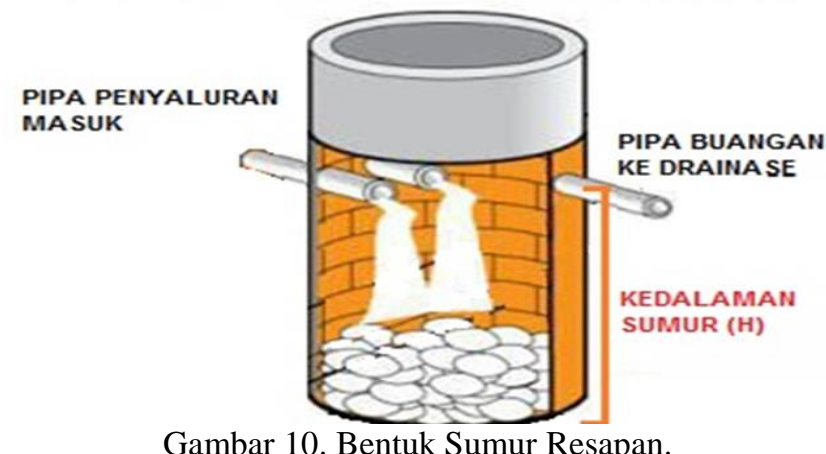

\section{SIMPULAN}

1. Tebal lapisan lapangan yang direncanakan $60 \mathrm{~cm}$, terdiri dari 3 lapisan yaitu :

a. Lapisan pertama (Top layer) setebal $20 \mathrm{~cm}$ menggunakan rumput, pasir urug dan pupuk kandang dengan tebal 5 $\mathrm{cm}$.

b. Lapisan kedua setebal $20 \mathrm{~cm}$ yang terdiri dari pasir urug $5 \mathrm{~cm}$, dan pasir murni $10 \mathrm{~cm}$, dan kerikil $=5 \mathrm{~cm}$

c. Lapisan ketiga setebal $20 \mathrm{~cm}$ yang terdiri dari lapisan batu koral.

d. Saluran drainase pipa Lapangan berdiameter $12,5 \mathrm{~cm}$ dengan jarak $5 \mathrm{~m}$, dan dipasang pada kedalaman $0,60 \mathrm{~m}$ dari atas permukaan tanah .

2. Pada saluran pembuangan atau selokan di pinggir sekelilingan lapangan dipakai drainase persegi dan Saluran tertutup (Lingkaran) yang ukuran nya seperti pada tabel dibawah ini :

\begin{tabular}{lccc}
\hline \multicolumn{1}{c}{ Penampang } & $\mathrm{B} / \mathrm{D}$ & $\mathrm{H}$ & $\mathrm{Q}$ \\
\hline Persegi panjang & 0,5 meter & 0,5 meter & $0,055 \mathrm{~m}^{3} /$ detik \\
Lingkaran & 0,8 meter & $0,8 \mathrm{~m}$ & $1,318 \mathrm{~m}^{3} /$ detik \\
Kolam Retensi & $8 / 6$ meter & 3 meter & $0,02 \mathrm{~m}^{3} / \mathrm{det}$ \\
Sumur resapan & 1 meter & 3 meter & $0,042 \mathrm{~m}^{3} /$ det \\
\hline
\end{tabular}

\section{DAFTAR PUSTAKA}

Badan Meteorologi Klimatologi dan Geofiska, (BMKG) Muaro Jambi.

Badan Standar Nasional 1994,Standar Nasional Indonesia no: 03-3646-1994 tentang tata cara Perencanaan Teknik Bangunan stadion ,Jakarta

Bambang Triatmodjo, CES. DEA. 2013. Hidraulika II. Yogyakarta: Beta Offset.

Chow ,Ven Te.1992,Hidrolika Saluran Terbuka ,Jakarta ;Erlangga

Dinas Pekerjaan Umum Tanjung Jabung Barat, (Bidang Pengairan dan Drainase), 2013

Hadisusanto, Nugroho, H.,Dipl., 2010. Aplikasi Hidrologi

Halim Asmar,.H.A., 2004. Drainase Perkotaan, Cetakan Kedua, UII Press Yogyakarta (anggota IKAPI).

Kalsim, Kusnadi, Dedi. 2010. Teknik Drainase Bawah Permukaan, Edisi Pertama Yoyakarta; Graha ilmu .

Kamiana, Made, I., 2011. Teknik Perhitungan Debit Rencana Bangunan Air, Edisi Pertama - Yogyakarta; Graha Ilmu.

Mulyonto, H.,R., 2013. Penataan Drainase Perkotaan, Edisi Pertama - Yogyakarta : Graha Ilmu.

Suripin.2004 ,Sistem Drainase Perkotaan yang berkelanjutan edisi pertama .Jogyakarta : Andi .

Wesli. 2008. Drainase Perkotaan, Edisi Pertama - Yogyakarta; Graha Ilmu. 